\title{
COMMENTARY The benefits of screening must outweigh the risks and costs
}

Gretchen L Birbeck
UCLA-Robert Wood
Johnson Clinical Scholar
10833 Le Conte Ave,
Factor B-545
Los Angeles, CA
90095-1736
Correspondence to:
Dr Birbeck
gdike@ucla.edu
Competing interests:
None declared
West J Med
2000;172:308-309

By instituting a simple screening program, Lohiya et al were almost able to eliminate enterobiasis from their population of institutional residents. Despite the initial cost of mass treatment, they realized a decrease in their overall costs within two years of starting the program. The authors' success provides an opportunity to review screening programs and consider when and why some can be effective, while others, although equally important, can be ineffective or even harmful to patients. Population screening can be done with three purposes in mind.

First, screening can be carried out for the direct benefit of patients. Many of our interventions based in the community, such as offering blood pressure checks at health fairs, are geared toward helping individuals. Second, screening can be used for the protection of others. Several such tests are routinely conducted on donated blood products to prevent the transmission of infectious agents. Finally, screening can be performed simply to gather baseline information on individuals or populations.

When assessing the potential value of any screening program, it is important to clarify the purpose of the program. The screening program presented here benefited both the screened persons, who were guaranteed treatment after a single positive test result, and other residents of the facility, particularly the roommates of infected people.

Of course, screening for all possible conditions, even in a selected group, is impossible and undesirable. Unless 
screening is being conducted to provide data for academic or public health use, various factors should be considered. The condition that is being screened for should be either sufficiently common or devastating to warrant the time and expense. Neonatal screening programs for metabolic disorders identify only a few abnormalities in the population, but among them are preventable cases of severe neurologic disability.

Early diagnosis must be associated with better outcomes. Major concerns regarding the outcomes of patients who are screened and treated for early prostate cancer have made screening with the prostate-specific antigen test a controversial issue. The treatment that produces better outcomes must also be available to the screened population.

The screening technique must be sensitive enough to identify most cases. The screening technique must be specific enough to avoid an excess of unnecessary treatments. Attempts to use pelvic sonography as a screening tool for ovarian cancer resulted in an unacceptably high rate of unneeded laparotomies. The possible consequences of false-positive results need to be considered when planning any screening program.

The cost and risks of screening should not outweigh the benefits. Cost includes the financial burden of the screening program and follow-up and the potential personal cost to the people being screened in money, time, and effort. Is there excessive anxiety or inconvenience associated with the screening test or the follow-up needed for positive test results? How does this balance against the possible benefit for each patient? When Indiana instituted mandatory screening for the human immunodeficiency virus (HIV) as a requirement for a marriage license, falsepositive results greatly outnumbered true-positive results. Within one year of beginning the program, a substantial proportion of Indiana residents were driving across state lines for their marriage licenses to avoid the expense of the HIV test. People were inconvenienced, and the state lost substantial revenues — all with little benefit.

The enterobiasis screening policy adopted at Fairview Developmental Center succeeded for several reasons. Enterobiasis, although not devastating, was common at the center, with an annual incidence of $15 \%$ to $31 \%$ in the years preceding the program. Early diagnosis and treatment of those infected and their close contacts led to better care for both the people tested and their roommates. Mebendazole is readily available and affordable, and this treatment exposed residents to few adverse effects. Due to the low cost and low toxicity associated with mebendazole use, specificity in screening and treatment were successfully compromised to increase sensitivity. Contact screening imposed in the earlier policy entailed an invasive and a resource-consuming process that probably had poor sensitivity for identifying newly infected persons. The improved screening technique and more aggressive/expansive treatment policy described by Lohiya et al decreased infection rates and overall cost.

\section{An unexpected present}

The young woman was clearly visible from the consulting room window, her emanciated frame draped in the tattered remnants of a sari, with a marasmic toddler balanced on her hip. She begged for food and alms, reaching wordlessly through the open windows of the buses parked at the bus stand.

She frequently pointed to the toddler, her eyes eloquent and beseeching. Few could hold out against this poignant appeal, and she made a good living. I watched her every day and noticed her abdomen getting bigger. On my way home from work one day, I inquired, "Pregnant?"

"Yes."

"You must go to the municipal hospital. They will give you the tetanus toxoid injections and folic acid supplements. Your child will get free immunizations."

"The municipal hospital is not for people like me."

It was a futile argument. I found myself collecting hematinics and calcium tablets from medical representatives for her. I administered the tetanus toxoid injections, but could not persuade her to undergo any blood tests. So her blood group and HIV status remained unknown.

Six months later, hearing a commotion in the waiting room, I peered out. She was in labor, on the floor, watched in horror by the rest of the patients.

"Can you go somewhere else? This is only a consultation practice. I do not deal with childbirth."

Her only answer was a groan, after which she started to push. Frantic, I cleared the waiting room, and, after the lapse of 10 years, I conducted an amateur delivery, with no implements and no assistance. It was a healthy baby girl.

"Where will you go?"

"You know I have nowhere to go."

This was more than I had bargained for.

"Okay. You can spend the night on the veranda. Do you have a family?"

"No."

That was not possible. Had she sprung up like a weed?

"This birth has to be registered."

"Tomorrow doctor. I cannot move today."

The next morning she had disappeared. The veranda was wiped clean, and she had left me a present. It was caterwauling behind a stone bench, wrapped in a dirty piece of cloth.

There has been no trace of the mother in 15 years. The present has, in the meantime, grown into a sister for my other children.

Gita Mathai

Pediatrician in family practice

Vellore, Tamil Nadu, India 